\title{
E्द्धreatidara
}

\section{O Ateneu: uma análise de mecanismos disciplinares no romance de Raul Pompeia}

\author{
Tiago Ribeiro Santos \\ Rita de Cássia Marchi
}

RESUMO - O Ateneu: uma análise de mecanismos disciplinares no romance de Raul Pompeia. Este artigo apresenta uma análise sociológica do funcionamento dos mecanismos disciplinares descritos n'O Ateneu, romance de Raul Pompeia, escrito no século XIX. A representação do Ateneu como uma escola, isto é, como lugar de produção e preservação de ritos, crenças e técnicas que produzem um desejado efeito de disciplinamento sinaliza, na análise, uma possível aproximação entre os conceitos de poder simbólico de P. Bourdieu e poder disciplinar de M. Foucault aplicados ao cotidiano escolar. Assim, analisam-se as tecnologias disciplinares ordinariamente atribuídas ao espaço educacional abordando as posições dos agentes que participam da rotina disciplinar do Ateneu por meio de disposições, interesses e sentidos coletivamente construídos.

Palavras-chave: Mecanismos Disciplinares. Vida Escolar. Poder Simbólico.

\begin{abstract}
O Ateneu: an analysis of the disciplinary mechanisms in Raul Pompeia's novel. This article presents a sociological analysis of disciplinary mechanisms operation represented in O Ateneu, written by Raul Pompeia on 19th Century. The representation of Ateneu's institution as a school - or, in other words, a place of production and preservation of rites, beliefs and techniques that produce one desired disciplinary effect - in this analysis signalizes one approach between symbolic power concepts, from P. Bordieu, and disciplinary power, from M. Foucault, applied in the school quotidian. Therefore, we analyze the disciplinary technologies attributed to the educational space, approaching the positions of the agents that participate in Ateneu's disciplinary routine through provisions, interests and collectively constructed senses.
\end{abstract}

Keywords: Disciplinary Mechanisms. School Life. Symbolic Power.

Educação \& Realidade, Porto Alegre, v. 38, n. 1, p. 339-360, jan./mar. 2013. 


\section{Considerações Preliminares}

Este artigo decorre de pesquisa ${ }^{1}$ que tem por objetivo apreender e examinar o modo de atuação dos mecanismos disciplinares presentes no romance $O$ Ateneu de Raul Pompeia, obra da literatura brasileira publicada originalmente em $1888^{2}$.

No universo teórico deste estudo os mecanismos disciplinares são considerados como técnicas que estabelecem o controle do tempo, do espaço e das ações de sujeitos sobre os quais atuam, visando produzir tanto utilidade quanto submissão (Foucault, 2005). Compreende-se que, enquanto técnicas práticas de uma estrutura hierárquica de relações de poder, estes mecanismos arquitetam um universo de microforças inerentes aos meios educacionais operantes sobre o indivíduo no espaço escolar (neste caso, no colégio Ateneu). Como aparatos que integram uma engenharia institucionalmente específica, estas tecnologias potencializam a força e a utilidade dos indivíduos, sujeitandoos coordenadamente ao exercício apropriado às rotinas e às regras de conduta não somente previstas, mas prescritas naquele espaço. Isto não impede, no entanto, que ocorram resistências por parte dos submetidos a estes mecanismos, como veremos no caso do menino Franco, o eterno desviante e, ao mesmo tempo, o eterno desviado, porque submetido ao sempiterno escrutínio do olho que tudo vê. Aqui, nos referimos ao efeito pan-óptico descrito por Foucault a partir do caso Bentham (Foucault, 2005). Ou seja, a eterna vigilância e castigo infligidos a Franco pelo diretor do Colégio (Aristarco) é obtida pela proliferação, no interior daquele espaço escolar, da mais pura disciplina. Aquela que se exerce sem fazer força, embora geralmente imprima efeitos de poder (efeitos que podem, ou não, utilizar a força física do castigo corporal ou a força simbólica da humilhação). A disciplina que pode, enfim, apoiar-se na legitimidade da força que adestra. Isto é, que educa. Por isto, no romance, o caso do aluno Franco é exemplar e será abordado neste artigo ${ }^{3}$.

Se este estudo é informado pelos conceitos de disciplina, de mecanismos disciplinares e de micropoderes (ou de uma microfísica do poder) a partir da obra de Michel Foucault, adotamos da compreensão bourdieusiana, o seu conceito de poder associado ao universo escolar como universo de inculcação de um arbitrário cultural historicamente selecionado pela chamada classe dominante. O poder em especial aqui abordado, isto é, o poder disciplinar da escola (ignorando a redundância que os termos naturalmente podem implicar) carrega consigo a sobredeterminação da luta social e política mais ampla travada em sociedade: isto é, o poder de manter ou de transformar a estrutura social vigente. Assim, este artigo trata, mais amplamente, da forma educacional em seu sentido típico (para nos referirmos também a M. Weber e seu conceito de tipo ideal como instrumento de interpretação da realidade). Isto é, analisamos aqui, a partir do romance de Raul Pompeia, a forma educacional que historicamente logrou se espalhar, a partir da moder- 
nidade ocidental, como modelo para todas as direções e que, somente muito recentemente, é vista como estando a sofrer abalos em seu modelo de estruturação (ou construção) social ${ }^{4}$.

Assim, o romance de Pompeia, ao retratar (tal como o realismo funcionalista o faria) a vida interna em um colégio que muitos supõem ter sido por ele mesmo frequentado ${ }^{5}$, nos permite compreender aquilo que é enunciado por Bourdieu (1996a) no seu trabalho de dessacralização da obra de arte, isto é, na tomada da obra literária como objeto de pesquisa sociológica: a literatura pode, por vezes, dizer mais sobre o mundo social que muitos escritos com pretensão científica, mesmo que ela o diga "[...] de um modo tal que não o diz realmente" (Bourdieu, 1996a, p. 48). Deste modo,

\begin{abstract}
O "efeito de real" é essa forma muito particular de crença que a ficção literária produz através de uma referência denegada ao real designado que permite saber recusando saber o que ele é realmente. A leitura sociológica rompe o encanto. Colocando em suspenso a cumplicidade que une o autor e o leitor na mesma relação de denegação da realidade expressa pelo texto, ela revela a verdade que o texto enuncia, mas de modo tal que não a diz; além disso, ela faz surgir a contrario a verdade do próprio texto que, precisamente, define-se em sua especificidade pelo fato de que não diz o que diz como ela o diz (Bourdieu, 1996a, p. 48, grifo do autor).
\end{abstract}

\title{
A Leitura Sociológica do Romance
}

Esta análise d'O Ateneu toma como base a que Pierre Bourdieu realiza no prólogo de As Regras da Arte, tendo por objeto de estudo o romance A Educação Sentimental, de Gustave Flaubert. Por meio de uma leitura interna do romance, Bourdieu (1996a) extrai elementos da estrutura social nele enunciada e torna inteligível a distribuição das propriedades específicas dos agentes nela situados. Como resultado, o autor elabora o conceito que denomina campo do poder, demonstrando os efeitos determinados pelas posições que os agentes do romance ocupam naquela estrutura ${ }^{6}$. Neste sentido, o campo do poder deve ser compreendido

[...] ao mesmo tempo, como um campo de forças, cuja necessidade se impõe aos agentes que nele se encontram envolvidos e como um campo de lutas, no interior do qual os agentes se enfrentam, com meios e fins diferenciados conforme sua posição na estrutura do campo de forças, contribuindo assim para a conservação ou a transformação da sua estrutura (Bourdieu, 1996b, p. 50).

Deste modo, o conceito de campo do poder orienta também, nesta análise, o modo de apreensão das relações entre os agentes (persona-

Educação \& Realidade, Porto Alegre, v. 38, n. 1, p. 339-360, jan./mar. 2013. 341

Disponível em: <http://www.ufrgs.br/edu_realidade> 
gens) que constituem o romance aqui considerado. Mas, operacionalizar este conceito na obra literária demanda, como fundamento primário, a localização dos agentes no campo do qual participam. Localizar significa cartografar um espaço que condicione sua leitura, o que quer dizer, no sentido técnico, o desenho de uma planta que impõe direção e limites à análise (Bourdieu, 2004). Os elementos, fonte de tal representação cartográfica, são os indícios que Raul Pompeia fornece a respeito dos agentes que constituem o Ateneu. Isto é, são as diferentes posições e tipos de capital simbólico ${ }^{7}$ identificáveis em cada personagem que habita o colégio: o diretor, os alunos, os professores, os vigilantes; enfim, uma gama de agentes que detêm características inerentes à posição que ocupam no espaço escolar e que engendram uma estrutura de relações objetivas.

A objetividade atribuída às relações estabelecidas entre os agentes naquele espaço é o que torna possível pensar suas ações como estratégias que, variavelmente, podem provocar, a partir dos capitais específicos que lhe são próprios, a preservação ou mudança da posição que ocupam no campo. No entanto, se é aceitável que o conceito de relações objetivas que constitui dado campo pode, empiricamente, ser aplicado ao mundo social e também, neste artigo, ao mundo social circunscrito no romance, é preciso ainda fazer referência sobre as formalidades que, de forma delimitada, conduzem a produção literária.

Tem-se por pressuposto, quanto à escrita do romance, que "dar forma é também seguir as formalidades" (Bourdieu, 1996a, p. 48) que os agentes do campo literário preservam ao produzir literatura. Assim, $O$ Ateneu pode ser considerado produto de um estado razoavelmente autônomo do campo literário brasileiro, isto é, um resultado dos princípios da atividade literária de seu tempo.

Exigir do romance a possibilidade de uma leitura pura é exigir também um leitor puro, isto é, um leitor correspondente às exigências de um campo literário autônomo que produz, para Bourdieu, “[...] obras destinadas a serem decifradas, portanto, sujeitas à leitura repetida que é necessária para explorar, sem a esgotar, a polissemia intrínseca da obra” (1996a, p. 340). Daí compreende-se que o propósito de decifrar uma obra literária é possível devido às formalidades que o escritor opera no texto, propondo uma realidade que é eufemizada pelo discurso literário. Esta realidade permite que o leitor satisfaça certa vontade de saber que a experiência literária suscita, isto é, como efeito dos elementos implícitos que estruturam o percurso da aventura que o romance enuncia e que o ato da leitura permite acompanhar.

A suposição de um real mais profundo que o texto literário, em forma de eufemismo, anuncia, é o caráter que mobiliza a tentativa de extrair a lógica operacional dos mecanismos de disciplinamento n'O Ateneu. Entende-se que a estrutura que organiza a ficção e que fundamenta a impressão de realidade que a obra produz é resultado de uma 
linha tramada em um único tecido cujos elementos e personagens agem de maneira razoavelmente combinatória. Sem haver impedimentos de os personagens estarem sujeitos a um conjunto de forças que os atraem ou repelem entre si, os polos em que se situam é que mantêm a probabilidade de possíveis mobilizações num embate de interesses. A luta que determina a posição em que se situam fornece ao romance a condição de objeto que, em si mesmo, responde e corresponde aos próprios efeitos que lhe são de origem.

\section{A Docilidade Mecânica dos Rapazes}

Sérgio, o protagonista do romance, toma conhecimento do Ateneu a partir de festividades que presencia como espectador neste cosmo. Assim sendo, é preciso investir nas condições que permitem fazê-lo crer nos valores atribuídos a estas festividades e, extensivamente, ao Ateneu. $\mathrm{O}$ reconhecimento que o menino faz do espaço escolar como um lugar privilegiado é efeito de um encantamento socialmente produzido. Ou seja, o "deslumbramento" (p. 28) produzido em Sérgio pelas solenidades no colégio pode ser compreendido como um tipo de crença que o faz apostar suas fichas neste jogo a ser jogado com estratégias comuns, no entanto, a um "cálculo pobre de uma experiência de dez anos" (p. 31$)^{8}$ (de idade):

É fácil conceber a atração que me chamava para aquele mundo tão altamente interessante, no conceito das minhas impressões. Avaliem o prazer que tive, quando me disse meu pai que eu ia ser apresentado ao diretor do Ateneu e à matrícula. $\mathrm{O}$ movimento não era mais a vaidade, antes o legítimo instinto da responsabilidade altiva; era uma consequência apaixonada da sedução do espetáculo, $\mathbf{o}$ arroubo de solidariedade que me parecia prender à comunhão fraternal da escola (Pompeia, 1993, p. 30; grifo nosso).

É por meio de qualidades visivelmente inscritas no próprio corpo dos agentes que é possível pensar a produção da crença a partir das primeiras impressões que Sérgio mantém sobre o Ateneu. O "triunfo espetaculoso da saúde, da força, da mocidade" (p. 28) é a impressão que Sérgio configura sobre os eventos ginásticos do colégio. Eventos onde se registram o resultado de um investimento incessante de aperfeiçoamento do corpo marcado por repetições, posturas determinadas, gestos precisos, etc. Parafraseando Foucault (2005), pode-se dizer que o ginasta se tornou algo que (também) se fabrica na escola: a disciplina do exercício físico molda e torna o corpo perpetuamente disponível e se prolonga no automatismo dos hábitos. A disciplina, portanto, como uma anatomia política do detalhe, da minúcia e do ínfimo.

A partir da matriz foucaultiana e no âmbito da historiografia da educação física e da análise da modernidade pedagógica, Carvalho

Educação \& Realidade, Porto Alegre, v. 38, n. 1, p. 339-360, jan./mar. 2013. 
(2005) argumenta que os discursos sobre a educação física são objetos centrais para uma análise do discurso educacional moderno. Isso porque os mecanismos e tecnologias de poder aqui considerados tiveram seus pontos de aplicação e de geração no campo da escolarização. Se a emergência da educação física nos sistemas escolares ocidentais se manifestou combinando manobras de tipo militar (marchas, formações, posições), acrobacias, jogos, desportos e exercícios da ginástica sueca (aquela mesma que o professor Bataillard ministrava no Ateneu), foi essa última que, da virada do século até meados dos anos 40 , se mostrou e era reconhecida como referente pedagógico completo, isto é, como solução para a organização de uma prática de ensino "sujeita a técnicas de aplicação bem definidas e dirigidas pelos propósitos de uma socialização ampla - ou integral - que almejava corpos, intelectos e vontades" (Carvalho, 2005, p. 501) .

O sentido quase mágico que a exibição da ginástica desperta em Sérgio faz esquecer, como efeito, o rigoroso trabalho disciplinar que se esconde por trás dos resultados das "manobras perfeitas de um exército sob o comando do mais raro instrutor” (p. 27). O professor de ginástica, Bataillard, esta "formosura masculina e rija" "de músculos a estalar o brim do uniforme” (p. 28), é o agente que, como sua estética enuncia, já tem incorporado o mais legítimo capital simbólico que impõe o reconhecimento do valor do exercício ginástico.

Coordenando o evento, o Prof. Bataillard sorri "à docilidade mecânica dos rapazes” (p. 28). Mas, a que isto se deve senão à satisfação de participar das atividades de um pelotão de ginastas? Com "amestrada disciplina” (p. 28), Prof. Bataillard é o regente do espetáculo. É o agente regularizador do que se deve e do que se faz no espaço ginástico, servindo como motor de autonomização destas práticas no Ateneu. Esta condição faz perpetuar estas atividades à medida que Bataillard e seus ginastas conseguem produzi-las de acordo com determinadas necessidades do colégio, entre elas, a da produção de uma festa da ginástica.

Insistir no interesse que mobiliza os agentes a se disciplinarem e a serem disciplinados da maneira orquestrada, como na festa da ginástica no Ateneu, significa compreender que os agentes que já incorporaram as lógicas objetivas e práticas de determinada atividade não têm necessidade de formular finalidades para suas ações; nesse caso, para os afazeres ginásticos. Isto porque estão, os agentes, tomados por um tipo de illusio, que é o sentido dado pelo agente a respeito do jogo que participa. Estar possuído por uma illusio significa, para o agente, dispor de uma gama de valores e regras incorporados que estruturam o modo como joga o jogo, isto é, que despertam nele o interesse em jogar e que fazem do jogo um lugar de encanto (Bourdieu, 1996b).

A illusio que orquestra os exercícios ginásticos formando "pirâmides humanas sobre as paralelas, deformando-se para os lados em curvas de braços e ostentações vigorosas de tórax" (p. 28), age como 
componente elementar para a construção da realidade ginástica no colégio. E a festa da ginástica é o espaço onde os interesses podem ser mutuamente reconhecidos. Reconhecimento que não seria possível se não estivessem todos dominados pela mesma illusio. Ou seja, o que seria a festa da ginástica senão uma socialização da illusio? Para Bourdieu, socializar a illusio significa transformá-la em “collusio" (2005b, p. 43), gerando um espírito de corpo onde as afinidades são identificadas entre os agentes devido aos sentidos comuns atribuídos ao jogo ${ }^{10}$. O efeito que a illusio sustenta, reproduzindo no sentido do jogo as práticas já instituídas, permite pensá-la como condição na qual repousam as possibilidades dos investimentos constantes de disciplinamento que o exercício ginástico requer. A composição da força dos agentes, derivada de técnicas disciplinares em nome da ordem, agilidade, precisão, estética, etc., faz vir à luz o que se pode chamar de time, isto é, jogadores que visam o mesmo objetivo.

A entrada em determinados jogos depende do direito de deles participar. No caso da ginástica, depende das condições que assegurem a possibilidade de nela ingressar e reproduzir os seus princípios. Aqui a disciplina pode ser pensada como elemento fundamental de entrada e de exercício da atividade ginástica e que se instala como exigência tática que não precisa ser declarada como regra do jogo, uma vez que faz parte da regularidade deste. Sob efeito da incorporação da disciplina, reproduzindo movimentos precisos e controlados, os agentes colocam em prática disposições construídas ao longo do processo que os prepara como ginastas.

Sérgio, que o coração pulava "no peito com um alvoroço novo" (p. 28), é o agente, como já se disse, que presencia os espetáculos. Ele é o que sofre os efeitos da produção de crenças que o mundo da escola, aos seus olhos, encantado, é capaz de produzir. Formas tão íntimas de experimentar a escola, como a emoção que o "arrastava para o meio dos alunos, numa leva ardente de fraternidade” (p. 28), permite que nele se produza também uma forma de illusio, isto é, o seu sentido de estar no jogo. Mas, Sérgio é agente de illusio frágil, porque ainda desconhece as regularidades do jogo exercido no Ateneu, tendo suas raízes mais profundas no regime do jogo familiar sendo, principalmente, ainda uma "criança educada exoticamente na estufa de carinho que é o regímen do amor doméstico" (p. 21). Mas, adentrado ao colégio, as pressões que este mundo exerce em nome dos bons costumes, da pedagogia, da disciplina etc., hão de mostrar a ele como, de fato, se constroem homens no Ateneu.

\section{Tiranetes por Delegação}

As estratégias de preservação e reprodução da ordem vigente que os agentes dominantes no Ateneu (isto é, professores, bedéis e funcionários) acionam, dependem relativamente de um trabalho de cumpli-

Educação \& Realidade, Porto Alegre, v. 38, n. 1, p. 339-360, jan./mar. 2013. 
cidade com o grupo dominado. Por conseguinte, a condição que fundamenta a inculcação da necessidade do acordo que torna possível o funcionamento do campo do poder do Ateneu só pode ser procurada, como tem se tentado mostrar neste artigo, dentro dos limites da própria estrutura do campo. Os trabalhos de aproximação de sentimentos e interesses vistos até aqui a respeito do Ateneu, que estabelecem um acordo entre dominantes e dominados (como é o caso de Prof. Bataillard e seus ginastas) não podem ser exercidos senão através de um ponto de vista em comum. Os agentes, em posições diferentes, ao compartilharem o mesmo ponto de vista, estão severamente inclinados a orientar e reproduzir suas práticas sob os princípios de apreciação das regras do mundo social específico da posição dominante.

As motivações do diretor do colégio, Aristarco, em instalar e dispor de estratégias que preservem e perpetuem o regime disciplinar não pode encontrar outra justificativa senão nas próprias exigências provenientes da estrutura de relações de poder do colégio. Contudo, compreender o Ateneu como um campo dominado pelos agentes do poder institucional, como é o caso de Aristarco e seus pares, não significa inscrever o campo em um tipo de inércia. A "milícia da casa" (p. 53), formada por internos eleitos "por seleção de aristocracia" (p. 52), inscreve novas posições na estrutura de relações do Ateneu. Estes, recebendo o nome de "vigilantes", "armados de sabres de pau com guardas de couro" (p. 53), inseridos na lógica das operações disciplinares, são inclinados a incorporar todas as possíveis propriedades que a posição de vigilante lhes confere. Com efeito, assumir a posição de vigilante, significa também assumir as práticas do grupo dominante, isto é, por exemplo, a vigilância permanente, a imposição da ordem e o uso da força. $\mathrm{O}$ aparecimento de vigilantes delegados por Aristarco no Ateneu significa, assim, também fazer aparecer uma nova e mais complexa ordem na pirâmide hierárquica das posições no colégio. Aos não eleitos, cabe a penosa posição duplamente dominada, isto é, dominada pelos vigilantes eleitos que, por sua vez, são também uma fração dominada pelo grupo dominante representado por Aristarco. Esse movimento na estrutura do jogo de relações do Ateneu, que, como alquimia, transforma seus alunos em "tiranetes por delegação" (p. 53), permite ao grupo plenamente dominante instalar novas condições estratégicas dos mecanismos de disciplinamento. Com acréscimo, sem a necessidade da presença física do grupo dominante, os princípios disciplinares são estabelecidos por meio de delegação. Esta sendo possível com a condição de que os agentes vigilantes, isto é, a fração dominante entre os dominados, estabeleça o seu grau de adesão aos princípios do ponto de vista do grupo plenamente dominante.

A eleição do vigilante não supõe, em hipótese alguma, um mero sorteio de nomes. No sentido contrário, os eleitos a ocuparem o posto de exercício da vigilância legítima, isto é, a também compartilharem do mesmo "amor da regularidade da organização militar" (p. 52) instalado 
no Ateneu são eleitos porque dispõem de propriedades imprescindíveis ao cargo. Poder-se-ia perguntar, então, o que fundamenta esse processo de deslocamento da posição dominada a uma fração da posição dominante?

Operando dentro de uma economia de trocas, os agentes que alcançam posições de destaque em diversas áreas, asseguram a possibilidade de serem reconhecidos como os mais aptos a corresponder às exigências do jogo escolar. Em suma, os agentes que dispõem de condutas regularizadas pela ordem social do Ateneu são os mais inclinados a receber os méritos consagrados no microcosmo escolar. Um agente adaptado às regularidades deste microcosmo e predisposto a levá-las a sério detém condições possíveis de apropriar capital simbólico. Contudo, o capital simbólico apenas cumpre sua eficácia se for reconhecido por determinado grupo, o que implica em respeito, autoridade e confiança nas palavras e nas práticas daquele que detém o capital simbólico mutuamente reconhecido. É o diretor Aristarco quem, ocupando uma posição privilegiada, pode fazer serem percebidos e apreciados os agentes por ele reconhecidos como detentores desse tipo de capital simbólico. Com efeito, Aristarco pode, assim, classificar os eleitos tendo como fundamento o capital simbólico reconhecido sobre cada agente. Aristarco, como se vê, é capaz de agenciar estratégias de posição à tomada de posição dos agentes dominados, tendo como matriz a disposição reconhecida sobre estes mesmos agentes.

Ter incorporado a lógica da estrutura de funcionamento de determinado campo significa, para o agente, ser detentor de um habitus. O habitus, de acordo com Bourdieu (1983, p. 105), "aquilo que se adquiriu, mas que se encarnou no corpo de forma durável sob a forma de disposições permanentes", exerce a função de ligamento entre agente e estrutura. É a partir da incorporação do habitus de vigilante que é possível pensar a fidelidade às regras que o agente mantém. Dispor do habitus de vigilante significa perceber e apreciar o universo do Ateneu com categorias de classificação e desclassificação de atitudes e atividades próprias de um vigilante. Como resultado, o habitus acaba por exercer também um papel de distinção, considerando que ele inscreve nos agentes propriedades apenas identificáveis na relativa raridade da sua forma de ser, agir e pensar enquanto vigilante. Dito de outra forma, o habitus inscreve nos agentes um sistema de códigos muito particulares que orientam suas ações. Neste sentido, exercer os atos atribuídos à posição de vigilante não significa apenas dispor de condições para regularizar a ordem no Ateneu. Ser vigilante significa ser percebido e reconhecido como tal, isto é, significa dispor de condições que preservem e atribuam legitimidade ao estatuto de vigilante; tal condição não podendo ser alcançada senão pela adaptação de sua conduta mediada por esse habitus particular.

Os vigilantes, como reivindicadores do exercício disciplinar, sem deixar de exercer as práticas que lhes cabem como internos, frequen- 
tam, por isso, os mesmos lugares que os outros alunos e são, assim, capazes de acessar os poros mais estreitos e inacessíveis do Ateneu, isto é, lugares menos comumente acessíveis ao grupo plenamente dominante. Trata-se dos quartos, dos lugares de banho, bem como do lugar ocupado por aquele que se senta ao lado no refeitório, podendo ser, agora, um vigilante por excelência. O que se vê, com a delegação de poderes, é uma nova capacidade de penetração do poder. Tal e qual disserta Foucault (2005, p. 144) a respeito dos acampamentos militares, são instalados, por infiltração, observatórios móveis de poder no Ateneu pela constituição de um "controle interior, articulado e detalhado".

Para o dominado, experimentar a relação com o dominante significa experimentá-la por meio de mecanismos a serviço deste. A disciplina, como condição primária para o estabelecimento de afazeres comuns a determinado grupo, não pode ser concebida na prática senão por meios específicos, isto é, mecanismos objetivados em produzi-la. Os vigilantes, que "tomavam a sério a investidura do mando" (p. 53), como agentes aderentes ao exercício da produção da disciplina, estavam sujeitos a cometer as violências mais visíveis de sua posição. Sérgio, levado "brutalmente à espada" (p. 69) pelo vigilante Sanches, é um dos agentes a sofrer dos efeitos dessa violência na sua forma mais grosseira.

Dispostos a corrigir as irregularidades mais visivelmente diminutas da conduta, tornando-as penalizáveis, os vigilantes são adequados como agentes de complementaridade do campo do poder. Isto quer dizer que eles exercem uma função de interdependência que tenta manter unidos os agentes do grupo dominado às adequações das normas a serviço do grupo dominante. Para Foucault (2005, p. 149), "tudo o que está inadequado à regra, tudo o que se afasta dela", isto é, os "desvios" compõem o rol de situações passíveis à força sancionadora da disciplina. Os efeitos do exercício disciplinar, isto é, a normalização das condutas é também tentativa de inculcar, à custa de sua força, um habitus no agente.

\section{Franco, ao Pelourinho}

As sanções disciplinares do e no Ateneu, sobretudo as ocorridas por meio de severas punições, podem ser concebidas como chamados à ordem. Ocasionalmente, estes chamados podem acontecer por meio de gestos, discursos, práticas, etc. como uma invocação ao agente para se adequar às regularidades do campo, o que lhe dá o direito de nele estar e permanecer. Mais precisamente, o chamado à ordem é uma reivindicação do senso comum produzido no campo, promovendo, por meio dos agentes que detêm este senso, de delicadas a grosseiras formas de admoestações sobre ilicitudes eventualmente visíveis.

Tal e qual os chamados à ordem, os mecanismos disciplinares exercem um apelo às normalidades institucionais, o que também quer 
dizer, às regras que impõem possibilidades e impossibilidades de ações no espaço em que o agente participa. Como alvo destes apelos, pode-se tomar a figura de Franco, recomendado "como incorrigível" (p. 44) por uma carta do pai ao diretor do colégio (Aristarco), "pedindo severidade" (p. 44) na educação do filho. Este pedido de ordem familiar, crendo nas (e recorrendo às) competências do espaço escolar, inscreve desde cedo em Franco a necessidade de investimentos objetivados numa suposta correção de conduta. Este fato coloca o menino em posição de desamparo, isto é, na posição de um agente sem referências senão a de ser incorrigível por assim ser. Cabe lembrar que acreditar na capacidade de correção da escola significa dispor de códigos de percepção e apreciação que lhe atribuam esse sentido. É por meio desta fórmula geradora de pensamento que é possível que sejam instaladas no Ateneu formas de correções autônomas, no sentido de que não estão subordinadas a leis externas em relação ao campo em que se situam e sendo, assim, capazes de corresponder às necessidades que esse campo produz:

$$
\begin{aligned}
& \text { - Ali está um de joelhos...? } \\
& \text { - De joelhos... Não há perguntar; é o Franco. Uma alma } \\
& \text { penada. Hoje é o primeiro dia, ali está de joelhos o Franco. } \\
& \text { Assim atravessa as semanas, os meses, assim o conheço } \\
& \text { nesta casa, desde que entrei. De joelhos como um peni- } \\
& \text { tente expiando a culpa de uma raça. O diretor chama-lhe } \\
& \text { cão, diz que tem calos na cara. Se não tivesse calos no jo- } \\
& \text { elho, não haveria canto do Ateneu que ele não marcasse } \\
& \text { com o sangue de uma penitência (Pompeia, 1993, p. 43). }
\end{aligned}
$$

A posição em que se encontra Franco pode ser apreendida como uma posição de destaque. Destaque no sentido de representar uma posição cujas propriedades são distintas em relação às propriedades comuns a outros agentes de seu espaço. As propriedades que acentuam sua posição, isto é, "de joelhos", "com calos" e "como um penitente" (p. 44), inscrevem em Franco as possíveis marcas que condicionam o reconhecimento de um agente em degradação. Este tipo de declínio, porém, apenas pode ser assegurado por meio de uma repetição incessante, atravessando assim "as semanas, os meses" (p. 44). Como resultado, esta repetição se inscreve como rotina inerente ao Ateneu que, desse modo, só pode ser introduzida por meio de um trabalho de rotinização de exercícios legitimado pela função corretiva atribuída ao espaço escolar.

Para os demais agentes, estar na posição oposta, livre dos mesmos açoites que ferem Franco, é gozar da ausência de agonias provocadas pelos efeitos das penalidades. No entanto, tornar públicas as penas de Franco, isto é, fazê-las serem cumpridas aos olhos de todos os agentes que participam do campo é também inclinar esses agentes ao efeito de não esquecê-las. O sentido ritualizado da pena, ocupando um espaço de destaque, permite com que ela seja percebida e nunca esquecida em seu modo operante e em suas implicações. Ou seja, faz da publiciza-

Educação \& Realidade, Porto Alegre, v. 38, n. 1, p. 339-360, jan./mar. 2013 349

Disponível em: <http://www.ufrgs.br/edu_realidade> 
ção da pena, um mecanismo não apenas de efeitos humilhantes sobre o agente que a sofre, mas, também, um mecanismo de reconhecimento público da infração. Em suma, a aplicação de penalidades disciplinares que, como diz Foucault, "pune baixando e degradando” (2005, p. 151), inclinam os agentes que as sofrem às posições mais marginais impondo demarcadores de diferenças. O que quer dizer, demarcadores que fazem vir à luz os agentes regularizados e não regularizados às regras do espaço escolar.

"Adianta-te, Franco", mandou Aristarco. Com a insensibilidade pétrea que o encouraçava para as humilhações, saiu Franco do lugar e de cabeça baixa, como um cão, foi parar no centro da sala. Ali esteve por alguns segundos, exposto, no meio do enorme quadrado de alunos. Os olhares caiam-lhe em cima, como os projéteis de um fuzilamento (Pompeia, 1993, p. 76).

Com exemplos abundantemente consideráveis retratados no romance, as admoestações exercidas sobre Franco obtêm o mais elevado grau de visibilidade no Ateneu. A mecânica da distinção, que produz um agente singularizado por meio da posição que ocupa no espaço, encontra sua força geradora em ações conjuntas aos demais agentes. Esta força, empregada coletivamente por um chamado à ordem das regularidades no Ateneu, gerando pressões sobre a figura de Franco, tende a expressar e inculcar as disposições reprobatórias do espaço escolar. O "enorme quadrado de alunos" (p. 76), estrutura física e simbólica que expressa a exatidão da norma, isto é, que configura limites sólidos e por isso claramente evidentes, não pode ser formado senão por cada um desses alunos. Na condição de semelhantes entre si, os agentes que detêm as regularidades das condutas aprovadas no e pelo Ateneu, exercem um tipo de pressão sobre Franco. Deve-se lembrar de que este, posicionado em sentido contrário ao de seus pares pode, sob os efeitos da comparação, ser percebido como um ser diferente, o que o inclina aos efeitos de constrangimentos da posição. Os agentes não normalizados, que mantêm inscritas em suas propriedades as irregularidades convencionadas pela norma, garantem visivelmente necessidades que só podem ser satisfeitas por meio de um trabalho de normalização. Como resultado, pode-se considerar que a diferença, um conjunto de fatores que constituem o ser percebido como diferente, só pode ser produzida e tornada visível ao serem instituídos mecanismos que produzam um tipo de normalidade.

Resistindo às regras do campo e, com efeito, recebendo os chamados à ordem para se adequar a este, Franco está altamente inclinado a sofrer as pressões do grupo dominante por meio de mecanismos disciplinares. Os mecanismos que sobre ele operam conferem as necessidades do direito de entrada no campo, isto é, disposições reconhecidamente inerentes do e no campo e, por isso, requeridas como tais para nele estar. Com efeito, ao relutar em se adequar ao conjunto de normas 
estabelecidas, o que o comprime a penalidades cada vez mais incessantes e rotineiras, Franco tem seu espaço de ação no campo estreitado, uma vez que não detém ou sendo negativo o seu capital simbólico.

Considerando que, para Foucault, “castigar é exercitar” (2005, p. 150), isto é, submeter, por meio da pena, o agente a uma rotina de exercícios condizente aos deveres do espaço, tende sobre Franco uma série de coações que implicam em um batente de repetições intensas das práticas mais comuns no Ateneu. Escrever é uma delas. "A necessidade de escrever por castigo" (p. 77), chegando a fazer "calos ao canto das unhas" (p. 77) de Franco, assinala o fato de que, ao lado das punições “copiadas ao modelo judiciário” (Foucault, 20005, p. 150) (que envolvem flagelos corporais), os sistemas disciplinares privilegiaram as punições da ordem do exercício - um aprendizado intensificado porque inúmeras vezes repetido. Castigar é exercitar! Por isto, para La Salle (1836 apud Foucault, 2005, p. 150) "O castigo escrito é, de todas as penitências, a mais honesta para um mestre, a mais vantajosa e a que mais agrada aos pais [...]" porque permite tirar dos próprios erros da criança maneiras de corrigir seus defeitos. Assim conformado, o castigo disciplinar tem, de acordo com Foucault (2005, p. 150), "a função de reduzir os desvios”.

Delegada por Aristarco, a pressão que insiste no trabalho da "interminável escrita” torna acessível a Franco, por esta estreita via de punição, a possibilidade de mudar sua posição degradada. Mudança no sentido de que, cumprir a pena, significa se apropriar, disciplinadamente, dos ensejos que a mesma suscita para aperfeiçoar (por exemplo) sua escrita (o que não se efetivou). Ainda que por meio da punição e, por isso, realizado com mais intensidade pela coerção, o exercício da escrita adéqua-se às exigências da produção mais simples do universo escolar que consiste em ter como resultado formas visíveis e, por isso, passíveis de classificação. Isto é, formas que possam ser avaliadas como, por exemplo, a caligrafia, o respeito às margens e linhas, o tempo utilizado no exercício, etc. Uma série de elementos, enfim, que, uma vez julgados, possam legitimar a necessidade de outras medidas coercitivas de correção agora dissimuladas; isto é, não mais a título de punir para corrigir, mas, de corrigir para aperfeiçoar.

A necessidade de instituir Franco no Ateneu, isto é, de instaurar sobre ele esquemas de pensamento que o façam reconhecer a regularidade das práticas no e do colégio e, por meio disto, incliná-lo a adotá-las, assegura a constância de sua posição no campo. Uma constância, como se tem dito, um tanto árdua no sentido em que o situa à margem das relações ordinárias, sendo seu nome evocado somente sob as condições mais submissas e degradantes. Isso assinala sobre ele uma trajetória de intermináveis chamados à ordem. Assim, Franco pode ser apreendido como o principal agente a ter as suficiências do sistema disciplinar do Ateneu testadas e que, dadas a sua teimosa resistência à ordem instituída, são testadamente levadas ao extremo.

Educação \& Realidade, Porto Alegre, v. 38, n. 1, p. 339-360, jan./mar. 2013. 
O extremo dos castigos físicos escolares é também relembrado pelo escritor Pedro Nava (1973) em suas memórias de aluno de colégio de elite, no Rio de Janeiro, no início do século XX. Ao se referir às "punições físicas” e ao "reinado da palmatória” (Nava, 1973, p. 283) que faziam parte da disciplina escolar do imperial colégio Pedro II, o memorialista faz alusão à morte de Franco no romance de Pompeia, afirmando que estas práticas se perdiam "nas trevas do tempo" (Nava, 1973, p. 283) tão antigas e instituídas (normatizadas) elas haviam sido na modelar instituição de ensino na qual estudou. Referindo-se particularmente à "cafua" (que provocou a morte de Franco no Ateneu), este autor se refere aos "tempos da pena de morte" (Nava, 1973, p. 283) no Pedro II, quando este ainda se chamava Seminário de São Joaquim:

Essa cafua existia no velho Seminário de São Joaquim com o nome de prisão dos alunos. (..) e vem descrita em O Ateneu, quando Raul Pompeia conta a detenção de que resultaria na moléstia e morte do Franco. O horrendo inpace, pelo desenho do autor, devia ficar nas umidades dum porão, onde o enterrado vivo, na companhia de ratos e baratas, escrevia páginas e páginas do castigo passado. No nosso internato parece que ela existia debaixo da escada que subia para os dormitórios (no meu tempo já era simples depósito de material escolar) e a ela referiam-se, com saudade, velhos inspetores como o Oliveirinha, o Candidinho e até o nosso bondoso Militão. (Nava, 1973, p. 329 , grifos do autor)

\section{Consideracões Complementares: o poder disciplinar em M. Foucault e o poder simbólico em Pierre Bourdieu}

Finaliza-se este artigo tratando da tomada de posição epistemológica em relação ao modo de conceber a disciplina através dos conceitos de poder disciplinar em Michel Foucault e de poder simbólico em Pierre Bourdieu. Tem-se ciência de que a aproximação teórica de autores com obras tão complexas e de amplos desdobramentos, como são as obras de Bourdieu e Foucault, não é tarefa fácil. No entanto, tem-se também ciência que, justamente, a amplidão e complexidade da abrangência dos seus conceitos são o que possibilita compreendê-los como conceitos em permanente construção. Isto é, as suas posteriores interpretação e utilização por pesquisadores dos mais diversos fenômenos sociais não está esgotada e nem é provável que o venha ser ${ }^{11}$. Apesar, portanto, das diferenças epistemológicas e metodológicas presentes nas perspectivas desses autores, essa análise pretendeu, especificamente, uma aproximação dos seus conceitos de poder. Entende-se que o poder, compreendido como simbólico em Bourdieu e disciplinar em Foucault, objetiva explicar um mesmo fenômeno: as forças que, tanto interna quanto externamente aos indivíduos, constituem as relações sociais que, como se sabe, são essencialmente políticas (pois o que nelas se disputa é poder, 
isto é, a potência de agir livremente nos mais variados campos da existência social).

O fato de Foucault não considerar, segundo muitos analistas, as variáveis de classe, gênero, religião, entre outros marcadores sociais baseando sua compreensão da vida moderna a partir de processos de longa duração - como é o caso da construção histórica e social do poder disciplinar; enquanto Bourdieu, ao contrário, enfatiza marcadores de classe que, segundo ele, definem as trajetórias sociais (pela aquisição de um habitus) - não impede que sejam aproximados para os fins que foram propostos para este estudo. Ou seja, considerar que a atuação do poder disciplinar (como definido por Foucault) no colégio Ateneu é também e, ao mesmo tempo, uma manifestação do poder simbólico (tal como definido por Bourdieu), é somente sugerir que, talvez, a capilaridade através da qual o poder opera nas sociedades disciplinares, segundo anuncia Foucault, possa ser compreendida como aquilo que torna a violência ou força que adestra (isto é, que educa), como uma violência essencialmente simbólica que tanto Bourdieu quanto Foucault reconhecem estar presente na vida escolar. Simbólica porque compartilhada, porque naturalizada, porque não pensada; isto é, não significada ou não compreendida como força ou constrangimento. A hipótese desse estudo é, portanto, a de que, em relação, pelo menos, aos conceitos de poder disciplinar e violência ou poder simbólico, estes autores podem ser compreendidos como contribuindo para o esclarecimento de um fenômeno social cuja temática é clássica porque fundadora das próprias ciências sociais (e, portanto, é dos mais instigantes): o quanto de ordem a regra garante? $\mathrm{E}$, inversamente, o quanto de regra a ordem produz?

As críticas que Bourdieu endereçou à Foucault dizem respeito principalmente ao fato de considerar que esse pensador não levava em conta, na sua obra, as condições sociais de possibilidade da razão científica (Callewaert, 2003). Isto é, o fato de Foucault não considerar os interesses, disposições e disputas inerentes ao processo histórico de construção do campo cientifico ${ }^{12}$. Embora Callewaert (2003) enfatize as divergências nos sistemas teóricos dos dois autores, o conceito de poder - que é o que aqui interessa - não é, no entanto, visto como intraduzível nos dois sistemas. É nessa brecha, portanto, que se considera ser possível sugerir aproximações entre os conceitos de poder disciplinar e poder simbólico, aplicados às relações disciplinares na escola, reafirmando que, do ponto de vista dessa análise, o poder disciplinar no espaço escolar é, essencialmente, também poder simbólico.

Os mecanismos disciplinares analisados neste estudo foram tomados como formas de constituição de um habitus (ou ethos), pois sendo o Ateneu definido como uma escola por Pompeia (e não como um hospital ou uma prisão) entende-se que a coerção institucionalizada e ali exercida sobre os agentes do campo, agiu no sentido que é próprio ou característico de toda instituição assim definida. A vinculação, por-

Educação \& Realidade, Porto Alegre, v. 38, n. 1, p. 339-360, jan./mar. 2013. 353

Disponível em: <http://www.ufrgs.br/edu_realidade> 
tanto, entre as teorias de Foucault e Bourdieu precede a análise propriamente dita e, até mesmo, a própria leitura do romance. No entanto, como visto, o ethos, assim como o habitus, é diferentemente construído entre e pelos agentes no espaço disciplinar. Dadas essas condições a respeito da configuração das normas do e no Ateneu, procurou-se nessa análise, então, situar a escola como lugar onde não apenas aplicam-se regras; mas como espaço de produção de condutas regulares. Um espaço de (re)produção da disciplina. E, portanto, um espaço produtor de subjetividades.

Frente a isto, entende-se a produção do indivíduo disciplinado como algo que resulta de mediações simbólicas entre os agentes que exercem, uns em relação aos outros, práticas disciplinares. Recorrese, portanto, à Bourdieu para pensar essas interações como essenciais para a inculcação da disciplina enquanto norma socialmente compartilhada. Se esta relação entre agentes foi pensada a partir de Bourdieu, o conceito de disciplina - pelo advento de uma sociedade disciplinar - é pensado, sobretudo, junto a Vigiar e Punir, de Michel Foucault (2005), devido às condições que esta obra fornece para identificar técnicas disciplinares que, de modo micro, operam nos diversos espaços institucionais.

A tese de Foucault (2005) em Vigiar e Punir é de que na Europa ocorre, nos séculos XVII e XVIII, uma descoberta do corpo como objeto e alvo do poder. Isto é, a ideia do corpo (e da vontade que o habita) como matéria moldável, como algo a que se pode dar forma. O corpo e sua conformação, portanto, como algo a ser produzido por uma técnica de poder específico: o poder disciplinar, que é o método que permite, doravante, o controle minucioso das operações do corpo, que realiza a sujeição constante de suas forças e lhe impõe uma relação de utilidadedocilidade (Foucault, 2005). Para Foucault (2005, p. 29), esta "fórmula geral de dominação" fez nascer uma "anatomia política" ou uma "mecânica do poder" diferente daquela que existia nos conventos, exércitos e oficinas. Assim, como método geral de dominação, a disciplina se distingue historicamente de seus antecedentes na escravidão, na vassalagem, na domesticidade, no ascetismo monástico. Para Foucault (2005, p. 119), o fato novo, no momento histórico do nascimento desta "arte do corpo humano", é que ela visa não somente o aumento das habilidades do corpo, nem somente aprofundar sua sujeição, “[...] mas a formação de uma relação que no mesmo mecanismo o torna tanto mais obediente quanto é mais útil e inversamente" (2005, p. 119). Assim, a disciplina fabrica corpos submissos e exercitados; numa expressão, corpos dóceis. A disciplina se inscreve, portanto, no corpo e espírito, segundo Foucault. Disseminada no tecido social, moldando as instituições, a disciplina decorre de uma gama de saberes que surgem pouco a pouco e fundamentam sua imposição. Com efeito, a disciplina ou a "arte de dispor em filas” (Focault, 2005, p. 125), surge como forma regrada de coordenar as ações humanas em diversos espaços. Em outras palavras, é o dispositi- 
vo de saber e de poder que promove a sujeição às regras de conduta em instituições como a fábrica, o exército, a escola, o asilo, etc. De modo microfísico, este poder opera por meio de mecanismos como a determinação de horários, vigílias, punições, exames e posições estritas de corpo e lugar.

Assim, o processo de subjetivação que o poder disciplinar engendra foi considerado nessa análise também como produto do poder simbólico; isto é, como produto do reconhecimento tácito dos códigos que estão em jogo em uma determinada relação. O poder simbólico conta, portanto, com a adesão dos agentes que a ele estão sujeitos, efetuandose na forma de criação, reprodução ou transformação de crenças e valores socialmente aceitos. Sob essa condição, o poder simbólico é reconhecido como legítimo e, ao assim ser, é capaz "de fazer ver e fazer crer" (Bourdieu, 2005, p. 14), construindo formas de significar ou representar a realidade.

Se Bourdieu esteve preocupado em mobilizar a noção de poder para compreender os processos de dominação e reprodução social, enquanto para Foucault a noção de poder se fez necessária para compreender as relações que, na modernidade, constituem o sujeito e a verdade; a partir de suas definições de poder pode-se chegar à conclusão de que este, sobretudo, produz sentidos. Por isso, considera-se que as diferentes direções que os autores tomam na operacionalização do conceito de poder não impedem sua articulação. De fato, as diferentes formas de conceituar e mobilizar o conceito de poder reflete justamente a flexibilidade que caracteriza a sua compreensão no âmbito das ciências humanas.

A noção de poder como algo produtivo repele intenções de que seja analisado apenas de forma negativa, como censura ou como força que oprime e impede práticas sociais. Ao contrário disso, Foucault, especialmente, analisa o poder em sua positividade, isto é, em sua capacidade de produzir verdades como produtos das relações de poder e de conhecimento historicamente construídos. Daí pode-se dizer que, para este autor, o poder não é uma coisa em si; mas, uma relação (ou prática) que se exerce e que produz sujeitos, redes hierárquicas e verdades. Assim, em se tratando de poder disciplinar, Foucault (2005, p. 143) especifica que este

[...] é, com efeito, um poder que, em vez de se apropriar e de retirar, tem como função maior "adestrar"; ou sem dúvida adestrar para retirar e se apropriar ainda mais e melhor. Ele não amarra as forças para reduzi-las; procura ligá-las para multiplicá-las e utilizá-las num todo. Em vez de dobrar uniformemente e por massa tudo o que lhe está submetido, separa, analisa, diferencia, leva seus processos de decomposição até às singularidades necessárias e suficientes.

Educação \& Realidade, Porto Alegre, v. 38, n. 1, p. 339-360, jan./mar. 2013. 
Sabe-se, a partir do modo de análise apresentado em Vigiar e Punir, que Foucault não estava preocupado em apontar quais grupos ou agentes exercem o poder disciplinar. Foucault compreendeu a mecânica do poder em uma "forma capilar", isto é, a que se exerce no "nível dos indivíduos, atinge seus corpos, vem se inserir em seus gestos, suas atitudes, seus discursos, sua aprendizagem, sua vida quotidiana" (2006a, p. 131). Frente isto, ele se opõe à visão clássica do poder que centraliza no soberano o direito de seu exercício. Assim, esse autor sugere ultrapassar o quadro jurídico tradicional do poder - aquele da soberania- para integrar o corpo dos indivíduos, seus gestos, sua própria vida (Revel, 2005). Isto é, o poder como produtor de subjetivação, entendida como o processo de constituição de sujeitos, ou, mais exatamente, de subjetividades. Em relação à constituição da subjetividade, sabe-se que ambos os autores convergem para a ideia de que este processo é atravessado por relações historicamente determinadas. Estas relações aparecem materializadas na forma de práticas sociais, instituições, regras de conduta, linguagens, etc. Portanto, para os autores, investir no conceito de poder significa investir na compreensão da constituição de sujeitos e da ordem social em meio a uma trama histórica onde duelam forças pela imposição de um modo legítimo ou dominante de sujeito e de ordem social.

O sujeito, para Foucault, é objetivado por saberes que são colocados em exercício por meio de práticas sociais. A disciplina é uma das práticas que integra o processo de subjetivação. Ela faz funcionar um sistema regrado que orienta condutas, naturalizando-as porque marca profundamente os corpos na forma de disposições subjetivas. Assim, no caso da sujeição ao poder disciplinar e da subjetivação que é seu efeito, pode-se pensar, a partir de Bourdieu, sobre as condições que possibilitam aos agentes aderir à disciplina na forma de um habitus ${ }^{13}$. Este princípio procura inserir os agentes como participantes da construção da realidade disciplinar. Isso não abstrai, no entanto, a noção de que as relações de poder são exercidas a partir de uma "relação desigual e relativamente estabilizada de forças", conforme afirma Foucault (2006b, p. 250).

Compreende-se, do ponto de vista de Bourdieu, portanto, que a aceitação ou adesão às determinadas normas disciplinares é promovida por uma atribuição, pelo agente, de sentidos a estas regras. Neste caso, estas não se configuram como algo encerrado em si, mas como parte de uma complexa rede de relações, tal e qual um jogo em que o agente participa e do qual, portanto, aceita as regras. Com efeito, a regra não precisa ser vista, pelo agente, como tal, quando ela se torna uma regularidade no jogo, isto é, quando faz parte do seu sentido, sendo seu princípio orientador e o fundamento do interesse nele mantido (Bourdieu, 1990).

Diante do exposto, o viés foucaultiano aqui empreendido se deu como ferramenta de identificação das regras do processo disciplinar, 
ou seja, as normas que, como pequenas peças se articulando conjuntamente, engendram uma máquina de produzir subjetividades. A disciplina, conforme pensada por Foucault (2005), é ferramenta conceitual para a assimilação dos pontos interligados que formam o tecido chamado instituição ou poder disciplinar. No entanto, um tecido cujos fios são sustentados por agentes que se posicionam, agem e interagem em relações objetivas fundamentadas em sentidos (nos dois sentidos, de direção e significado) que sustentam a própria existência do espaço em que estão inseridas. Desse modo, os agentes se inscrevem e são inscritos em um sistema onde atribuem sentido às suas ações e às coisas deste sistema. Compreende-se que esse movimento admite uma atuação combinada do poder disciplinar e do poder simbólico, pois o reconhecimento da disciplina como regra imanente do jogo, depende da interiorização de sua exterioridade ${ }^{14}$.

Recebido em 30 de junho de 2011 Aprovado em 22 de abril de 2012

\section{Notas}

1 Esta pesquisa, realizada no âmbito do Mestrado em Educação da Universidade Regional de Blumenau (FURB), teve o financiamento da bolsa de demanda social da CAPES.

2 O romance narra a trajetória escolar do menino Sérgio que, aos onze anos, ingressa no colégio Ateneu. No primeiro dia de aula, o protagonista recebe seu uniforme, um número no depósito geral, conselhos sobre alguns deveres de conduta e adentra no processo de conhecimento das regras que regem aquele espaço escolar. Conhece também os professores, os internos e, sobretudo, o diretor Aristarco. No decorrer de sua trajetória no Ateneu, Sérgio se depara com conflitos de ordens disciplinares, pedagógicas e morais. Em alguns casos, como forma de resistência, insurge contra as ordens do colégio e, como resultado, sofre as sanções previstas na instituição.

3 Devido os limites externamente estabelecidos para este artigo não será possível, no entanto, realizar a análise do personagem Aristarco, diretor do Ateneu.

4 Esta discussão está presente nas obras, de fins dos anos 90 do século XIX, sobre a chamada crise das instituições sociais: crise da escola, crise da família, crise da infância, crise da autoridade.

5 O que nos levaria da fórmula do romance para a da literatura de memórias e, mais especificamente, para a literatura de formação (bildsroman), como é considerada, quando o protagonista da trama evoca as 'aventuras' vividas pelo próprio autor quando criança rumo à vida adulta. Isto é, quando a obra remete à formação do indivíduo-autor rumo à maturidade.

6 Bourdieu (1996a) realiza nesta obra também uma leitura externa do romance, isto é, analisa o estado de forças e posições dos agentes do campo literário em que a obra está inserida e do qual é produto. Assim, ele explora também o campo artístico francês do século XIX e toma como referência as estratégias de Flaubert, Baudelaire e Manet que subvertem a ordem simbólica da produção

Educação \& Realidade, Porto Alegre, v. 38, n. 1, p. 339-360, jan./mar. 2013. 
artística ao conquistarem autonomia em oposição às esferas políticas, econômicas e religiosas de sua época. Bourdieu demonstra, assim, as condições que tornam possível a autonomização da atividade artística frente às esferas às quais a arte estava mais ou menos subordinada. No presente estudo, a análise do romance $\mathrm{O}$ Ateneu é apenas interna, não se analisando as condições sociais (ou o campo literário) do final século XIX que tornaram possíveis as formalidades empregadas por Raul Pompeia.

7 O capital simbólico é, de acordo com Bourdieu (1996b, p. 149), "qualquer tipo de capital (econômico, cultural, escolar ou social)" percebido e reconhecido pelos agentes de determinado campo por meio de um esquema de pensamento que, em parte, é produto da incorporação da estrutura objetiva do campo em questão.

8 As frases ou palavras entre aspas duplas e seguidas de paginação foram todas retiradas da seguinte edição de O Ateneu: POMPEIA, Raul. O Ateneu: apuração do texto em confronto com o original e introdução: Therezinha Bartholo. 9. ed. Rio de Janeiro: Francisco Alves, 1993.

9 A emergência e universalização da educação física no currículo escolar do Ocidente como um conjunto de saberes e técnicas sobre o corpo é registrada em outras obras literárias que descrevem a vida escolar no início do século XX, como em Balão Cativo onde Pedro Nava (1973) se refere diversas vezes à “ [ginástica] sueca" nas memórias de sua vida de estudante interno num colégio da elite brasileira (o colégio Pedro II, no RJ).

10 Sempre há, no entanto, aqueles que estão inclinados a não atribuir o mesmo valor ao jogo, como o personagem Rômulo - o "último na ginástica pela corpulência bamba" (p. 53) - que se concentrava em outras práticas como "as complexas e delicadas funções de zabumba da banda" (p. 53), onde detinha outra forma de illusio. Pode-se dizer, assim, que há tantas formas de illusio como há espaços onde estas formas podem ser produzidas.

11 Essa possibilidade de abertura teórica é especialmente destacada por Machado (2006) em relação ao modo como o próprio Foucault concebia a teoria: como provisória, acidental, inacabada, dependente de um estado do desenvolvimento da pesquisa e do objeto levado em consideração. Isto é, a teoria, em Foucault, poderia sempre ser revista ou reformulada, pois, segundo Machado, sua metodologia formulou, mais que um sistema teórico fechado, um programa que desencadeava análises fragmentárias e transformáveis.

12 Bourdieu, mais ao término de sua carreira, questionou algumas posições de Foucault. Entre elas, a deste autor não fazer dos conceitos de genealogia e arqueologia instrumentos capazes de serem utilizados sobre sua (de Foucault) própria obra. Não se conhece, no entanto, publicações de Foucault a respeito da obra de Bourdieu (Callewart, 2003).

13 O habitus, no conceito de Bourdieu, significa uma disposição adquirida e incorporada pelo agente por meio de uma trajetória ao mesmo tempo individual e social. A escola, entre outras instituições, pode ser considerada, nas palavras de Bourdieu, uma "força formadora de habitus" (1998, p. 211), uma vez que inculca esquemas de pensamento capazes de fazer o agente produzir juízos a respeito de si e dos outros. Portanto, o habitus pode ter diversas configurações, uma vez que varia de acordo com as origens dos agentes que, em relação umas às outras, são razoavelmente diversas.

14 Em sintonia com a posição desse artigo, Revel (2005) assinala que, entre a publicação de Vigiar e Punir e os cursos no Collège de France (no fim dos anos

358 Educação \& Realidade, Porto Alegre, v. 38, n. 1, p. 339-360, jan./mar. 2013. Disponível em: <http://www.ufrgs.br/edu_realidade> 
70), Foucault começou a "trabalhar num outro modelo de aplicação do poder, o controle, que trabalha ao mesmo tempo a descrição da interiorização da norma [...]. (Revel, 2005, p.36, grifo nosso). Segundo esse autor, a passagem de uma leitura disciplinar da história moderna para uma leitura "contemporânea" do controle social correspondeu a um visível engajamento naquilo que o próprio Foucault chamou de "ontologia da atualidade".

\section{Referências}

BOURDIEU, Pierre. Questões de Sociologia. Tradução de Jeni Vaitsman. Rio de Janeiro: Marco Zero, 1983.

BOURDIEU, Pierre. As Regras da Arte: gênese e estrutura do campo literário. Tradução de Maria Lúcia Machado. São Paulo: Cia. das Letras, 1996a.

BOURDIEU, Pierre. Razões Práticas: sobre a teoria da ação. Tradução de Mariza Corrêa. Campinas: Papirus, 1996b.

BOURDIEU, Pierre. Sistemas de Ensino e Sistemas de Pensamento. In: BOURDIEU, Pierre. A Economia das Trocas Simbólicas: introdução, organização e seleção de Sergio Miceli. São Paulo: Perspectiva, 1998. P. 203-229.

BOURDIEU, Pierre. A Produção da Crença: contribuição para uma economia dos bens simbólicos. São Paulo: Zouk, 2004.

BOURDIEU, Pierre. O Poder Simbólico. 8. ed. Rio de Janeiro: Bertrand Brasil, 2005a.

BOURDIEU, Pierre. Esboço de Auto-análise. Tradução de Sergio Miceli. São Paulo: Companhia das Letras, 2005b.

CALLEWAERT, Gustave. Bourdieu, Crítico de Foucault. Educação, Sociedades \& Culturas, Porto, n. 19, p. 131-170, 2003.

CARVALHO, Luis Miguel. Explorando as Transferências Educacionais nas Primeiras Décadas do Século XX. Análise Social, Lisboa, v.XL, n. 176, p. 499-518, jul./set. 2005.

FOUCAULT, Michel. Vigiar e Punir. Tradução de Raquel Ramalhete. 30. ed. Vozes: Petrópolis, 2005.

FOUCAULT, Michel. Sobre a Prisão. In: FOUCAULT, Michel. Microfísica do Poder: introdução, organização e tradução: Roberto Machado. 22 ed. Graal: Rio de Janeiro, 2006a. P. 129-143.

FOUCAULT, Michel. Sobre a História da Sexualidade. In: FOUCAULT, Michel. A Microfísica do Poder: introdução, organização e tradução: Roberto Machado. Graal: Rio de Janeiro, 2006b. P. 243-276.

MACHADO, Roberto. Introdução: por uma genealogia do poder. In: FOUCAULT, Michel. A Microfísica do Poder: introdução, organização e tradução: Roberto Machado. Graal: Rio de Janeiro, 2006. P. VII-XXIII.

NAVA, Pedro. Balão Cativo. Memórias/2. Rio de Janeiro: Livraria José Olympio Editora, 1973.

POMPEIA, Raul. O Ateneu: apuração do texto em confronto com o original e introdução: Therezinha Bartholo. 9. ed. Rio de Janeiro: Francisco Alves, 1993.

REVEL, Judith. Foucault - conceitos essenciais. São Carlos: Clara Luz, 2005.

Educação \& Realidade, Porto Alegre, v. 38, n. 1, p. 339-360, jan./mar. 2013 
Tiago Ribeiro Santos é mestrando no Programa de Pós-Graduação em Educação da Universidade Regional de Blumenau (FURB), em Blumenau, Santa Catarina, na linha de pesquisa Educação, Cultura e Dinâmicas Sociais. Graduado em Comunicação Social (2009) pelo Instituto Blumenauense de Ensino Superior (IBES).

E-mail: tiago.ribeiro@live.com

Rita de Cássia Marchi é doutora em Sociologia Política (UFSC/PARIS V). Mestre em Antropologia Social (UFSC). Professora pesquisadora do Mestrado em Educação e do Curso de Ciências Sociais da Universidade Regional de Blumenau (FURB), em Blumenau, Santa Catarina.

E-mail: rt.mc@bol.com.br 